Full Length Article

\title{
The role of empathy in crisis communication: Providing a deeper understanding of how organizational crises and crisis communication affect reputation
}

\author{
Lieze Schoofs $^{\mathrm{a}}{ }_{*}$, An-Sofie Claeys ${ }^{\mathrm{a}}$, Aurélie De Waele ${ }^{\mathrm{b}}$, Verolien Cauberghe ${ }^{\mathrm{b}}$ \\ ${ }^{a}$ KU Leuven, Institute for Media Studies, Faculty of Social Sciences, Parkstraat 45, 3000, Leuven, Belgium \\ ${ }^{\mathrm{b}}$ Ghent University, Department of Communication Sciences, Faculty of Political and Social Sciences, Korte Meer 11, 9000, Gent, Belgium
}

\section{A R T I C L E I N F O}

\section{Keywords:}

Crisis communication

Corporate reputation

Empathy

Attributions of responsibility

Apologies

\begin{abstract}
A B S T R A C T
This study advances our theoretical knowledge of how organizational crises and crisis communication affect reputation. Prior research solely emphasizes the importance of organizational crisis responsibility in this process. Three experiments show that stakeholders' empathy toward the organization provides a second explanation. The first two experiments demonstrate that victim crises not only inflict less reputational damage than preventable crises because stakeholders consider the organization less responsible for the events, but also because they are more likely to empathize with the company. The third study shows that empathy can also explain the outcomes of crisis communication. An apology arouses empathy among stakeholders and subsequently increases reputation repair, unlike denial. The role of empathy in the crisis communication process has implications for both theory and practice.
\end{abstract}

\section{Introduction}

Experimental research has contributed significantly to theory building in crisis communication by causally examining how the characteristics of an organizational crisis determine reputational damage as well as the effectiveness of crisis response strategies (Coombs \& Holladay, 2002; Coombs, 1998). This stream of research has identified the extent to which the organization is considered responsible for the crisis as a key determinant of post-crisis reputation and as crucial in determining a suitable response. As a consequence, crisis communication scholars have almost exclusively focused on attributions of crisis responsibility to understand the link between crises, crisis communication, and post-crisis reputation (Fediuk, Coombs, \& Botero, 2012). However, factors other than responsibility attributions may also play a part in explaining how stakeholder responses to crises are shaped, and might subsequently help inform the effective use of crisis communication (Coombs \& Holladay, 2005).

This study borrows insights from social-psychological research on interpersonal forgiveness to expand the understanding of the mechanisms underlying the impact of crises and crisis communication. Similar to crisis communication research, research on interpersonal relationships demonstrates the importance of responsibility attributions for interpersonal forgiveness (Weiner, Graham, Peter, \& Zmuidinas, 1991). Another crucial determinant of forgiveness, however, is empathy for the offender. People are more likely to forgive wrongdoers when they empathize with them (McCullough, Worthington, \& Rachal, 1997). This study proposes that stakeholders' empathy with an organization in crisis similarly reduces reputational damage.

By means of three experiments, this study explores the role of empathy as a driver of stakeholder responses to crises and crisis communication. The first two studies examine stakeholders' empathy with an organization as an explanation mechanism in the crisis type/reputation relationship, in addition to responsibility attributions. The results will lead to a more thorough understanding of how crises affect organizational reputations. The third study examines empathy as an explanatory factor for the outcomes of crisis response strategies. We believe that the effectiveness of apologies in response to an organizational crisis, which has been established in much prior research (Kim, Avery, \& Lariscy, 2009), can be explained through empathy. In interpersonal relationships apologies induce forgiveness because they increase victims' empathy for an offender (McCullough et al., 1997). Hence, a third and final study investigates whether an organizational apology evokes more empathy from stakeholders than denial.

\footnotetext{
* Corresponding author at: KU Leuven, Institute for Media Studies, Faculty of Social Sciences, Parkstraat 45 bus 3603 , 3000 , Leuven, Belgium.

E-mail addresses: lieze.schoofs@kuleuven.be (L. Schoofs), ansofie.claeys@kuleuven.be (A.-S. Claeys), aurelie.dewaele@ugent.be (A. De Waele), veroline.cauberghe@ugent.be (V. Cauberghe).
} 


\section{Conceptual framework}

\subsection{The role of responsibility attributions}

Much crisis communication research that aims to explain how crises shape stakeholder perceptions is guided by attribution theory (Coombs, 2015). This is a social-psychological theory that argues that people search for the underlying causes of, especially unexpected and negative, events to try to understand why an event occurred (Weiner, 1986). In the context of an organizational crisis, stakeholders will assess the degree to which organizational actions caused the events (Dean, 2004). The reputational threat posed by a crisis is considered a function of these attributions of crisis responsibility; the more responsible an organization is considered for a crisis, the more its reputation suffers (Coombs \& Holladay, 2002).

This reasoning forms the basic premise of the predictive Situational Crisis Communication Theory (SCCT; Coombs, 2007). SCCT categorizes various crisis types into three clusters based on the responsibility attributions they generate (Coombs \& Holladay, 2002). The victim cluster entails crises with weak attributions of organizational responsibility; the accidental cluster involves crises with certain, but low levels of organizational responsibility; and the preventable cluster includes crises for which the organization is held highly responsible. Experimental studies consistently demonstrate that reputational damage intensifies as the public attributes more responsibility to the organization (Coombs \& Holladay, 2002; Coombs, 1998; Lee, 2004), and that preventable crises have the most negative impact on reputation (Claeys, Cauberghe, \& Vyncke, 2010; Verhoeven, Van Hoof, Ter Keurs, \& Van Vuuren, 2012).

SCCT matches the three clusters of crisis types to three clusters of response strategies that vary in their responsibility acceptance for the crisis (Coombs, 2007). When using deny strategies, the organization rejects all responsibility for the crisis; diminish strategies minimize the organization's responsibility for the crisis damage; and rebuild strategies allow organizations to take full responsibility by offering apologies or compensating victims. Organizations should use deny strategies to respond to victim crises, diminish strategies to respond to accidental crises, and rebuild strategies to respond to preventable crises (Coombs, 2007). Hence, responsibility attributions forge a connection between the crisis situation and the most effective response (Coombs \& Holladay, 2002). Research on interpersonal forgiveness indicates, however, that besides responsibility attributions the empathy of stakeholders for the organization in crisis may play an important part as well.

\subsection{The role of empathy}

People ask forgiveness for their misdeeds, because forgiving typically involves letting go of negative affect and the motivation to retaliate against or to maintain estrangement from the offending relationship partner (Davis \& Gold, 2011; McCullough et al., 1997). Similarly, organizations in crisis seek forgiveness to overcome negative perceptions and to restore their relationship with stakeholders (Coombs, 2015). As in crisis communication research, prior research on interpersonal relationships has demonstrated that responsibility attributions play an important role in the forgiveness process. Victims who make benevolent attributions regarding a wrongdoer's behavior are more likely to forgive (Fehr, Gelfand, \& Nag, 2010; McCullough et al., 1998; Riek \& Mania, 2012). Responsibility attributions are, however, only one of the two most crucial determinants of forgiveness, as victims' empathy for an offending party has been identified as another key antecedent of forgiveness (Fehr et al., 2010; McCullough et al., 1997, 1998; Riek \& Mania, 2012).

Empathy is a multidimensional construct comprising cognitive and affective components. Cognitive empathy refers to cognitively taking another's perspective and allows for understanding the viewpoints, thoughts, and emotions of others (Baron-Cohen \& Wheelwright, 2004). Affective empathy refers to an emotional response in an observer to the emotional state or situation of another individual (Blair, 2005). This emotional response involves the experience of emotions that are congruent with the other's emotions (Decety \& Jackson, 2004). Affective empathy often goes beyond a matching of affect to result in compassion and sympathy for the other and a motivation to care for his or her wellbeing (Baron-Cohen \& Wheelwright, 2004).

Empathy has been shown to motivate a range of prosocial behaviors through increased concern for others (Davis, 2005). In a similar vein, prior research has consistently established that forgiveness is facilitated when victims of a transgression empathize with the wrongdoer (Davis \& Gold, 2011; Fehr et al., 2010; McCullough et al., 1998; Riek \& Mania, 2012). We propose that when stakeholders experience more empathy for an organization in crisis, they will be more likely to forgive the organization as well.

\subsection{Relationship between empathy, responsibility, and reputational damage}

Several theoretical models from social psychology have aimed to clarify the role of attributions of responsibility and empathy in the forgiveness process. McCullough et al. (1997) view forgiveness as a primarily empathy-driven phenomenon, and propose an empathy model of forgiveness. According to this model, empathy leads to increased caring for an offender, which overshadows the latter's hurtful actions. As a result, empathy is a central facilitative condition for overcoming victims' tendency to respond destructively following an offense (McCullough et al., 1997, 1998). Attribution theory proposes an alternative, parallel explanation for the forgiveness process. Based on this theory, forgiving is caused by attributional changes in relation to the offender (Weiner et al., 1991). When a victim interprets an offense as unintentional, he or she is more likely to forgive.

Numerous studies charting the antecedents of interpersonal forgiveness support both perspectives by showing that forgiveness is determined by both attributions of responsibility and empathy (Fehr et al., 2010; McCullough et al., 1998; Riek \& Mania, 2012). Yet, within these studies, the roles of empathy and responsibility attributions are investigated relatively independent from one another. Fincham, Paleari, and Regalia (2002) and Davis and Gold (2011), however, integrated both the empathy model of forgiveness and attribution theory into their own models. These authors propose that attribution processes occur causally prior to the development of empathy, which is the most proximal antecedent to forgiveness. When a victim perceives that an offending relationship partner did not intent to act offensively, the victim is more willing to forgive the transgression, and this can be explained in part because the victim is more likely to empathize with the offending partner. As such, more favorable responsibility attributions facilitate forgiveness both directly and indirectly through increased empathy.

These findings align with those from a limited number of studies that explored stakeholders' affective responses to organizational crises, which indicate that sympathy - considered an instance of the affective component of empathy (Baron-Cohen \& Wheelwright, 2004) - from the public is evoked when an organization is confronted with a victim crisis (Coombs \& Holladay, 2005; Mcdonald, Sparks, \& Glendon, 2010). However, despite this finding, further efforts to fully integrate public feelings of sympathy, let alone the more comprehensive concept of empathy, into (situational) crisis communication theory have not been made (Coombs \& Holladay, 2005; Coombs, 2007). The models proposed by the literature on interpersonal forgiveness provide, however, a framework for integrating both empathy and responsibility attributions as determinants of post-crisis reputation. Based on findings from interpersonal forgiveness and crisis communication theory, we expect that both perceptions of an organization's responsibility for a crisis and stakeholders' empathy with the organization will explain the relationship between crisis type and post-crisis reputation: 
H1. Victim crises inflict less reputational damage than preventable crises because they lead to lower responsibility attributions and higher levels of stakeholders' empathy.

The question, then, relates to the relative impact of empathy and responsibility attributions in affecting reputation. The empathy model of forgiveness (McCullough et al., 1997) and attribution theory (Weiner et al., 1991) represent two parallel perspectives that each stress the individual importance of empathy and responsibility attributions in affecting forgiveness. Both models receive considerable support in the social-psychological literature and suggest that empathy and responsibility attributions will mediate the crisis type/reputation relationship independently from each other. Scarce research that examines the relationship between these two mechanisms in the process of forgiveness suggests, however, that attribution processes will impact the development of empathy (Davis \& Gold, 2011; Fincham et al., 2002). This view is somewhat supported by studies in the context of crisis communication. The findings indicate a negative correlation between responsibility attributions resulting from the crisis type and public feelings of sympathy toward the organization (Coombs \& Holladay, 2005; Mcdonald et al., 2010). There relative importance in determining the post-crisis reputation, however, is unclear. Therefore, we propose the following research question:

RQ. How are attributions of organizational crisis responsibility and empathy related as mediators in the relationship between crisis type and post-crisis reputation?

\subsection{The organizational apology as a precursor to empathy}

If empathy helps explain the impact of crises, empathy might also help explain the impact of crisis response strategies. SCCT and related research argue that organizations can minimize reputational damage by accepting as much responsibility for a crisis as is being attributed to them (Coombs \& Holladay, 2002; Coombs, 2007). Numerous experimental studies have confirmed that a specific way of accepting responsibility, namely apologizing, results in increased reputation repair, especially compared to defensive strategies like denial (Decker, 2012; Kim et al., 2009; Lee, 2004; Sisco, 2012). However, while SCCT (Coombs, 2007) has outlined the conditions under which organizations should most certainly apologize, namely in the case of a preventable crisis, the underlying processes that account for apologies' positive impact on reputation repair have not yet received empirical research attention. Furthermore, apologies appear to be the most effective strategy even when the organization is not considered responsible for the events (Claeys et al., 2010; Kim et al., 2009). Given that the literature on interpersonal relationships shows that interpersonal apologies arouse empathy, we must consider empathy as an explanation for why apologies seem such an overall effective strategy in times of crisis.

Individuals are more likely to forgive a transgression when the transgressor has apologized (McCullough et al., 1997, 1998; Riek \& Mania, 2012; Tomlinson, Dineen, \& Lewicki, 2004). This relationship between apologizing and receiving forgiveness is considered a function of increased empathy with the apologizer (Davis \& Gold, 2011; McCullough et al., 1997, 1998). Offenders who apologize convey not only that they accept responsibility but also that they feel regret and emotional distress over their actions and the damaged relationship (McCullough et al., 1997; Tomlinson et al., 2004). The victim's recognition of the wrongdoer's distress arouses empathy with the wrongdoer (McCullough et al., 1997). As such, in the context of organizational crises, it can be assumed that an apology on behalf of the organization stimulates empathy in the public.

While most crisis communication research confirms that organizations should apologize for their misdeeds, some studies have shown that denial can also be an effective means of protecting reputations (Claeys et al., 2010; Fuoli, van de Weijer, \& Paradis, 2017). While apologies are likely to target the public's empathy for the organization, denial strategies aim to shape perceptions of responsibility. If the strategy succeeds in its purpose to eliminate perceptions of organizational responsibility, the crisis may no longer harm organizational reputation (Coombs, Holladay, \& Claeys, 2016). Nevertheless, we expect that if an organization is held responsible but denies a connection with a crisis, it is unlikely to induce empathy. Therefore, we expect the following:

H2. An apology results in increased reputation repair compared to denial because apologies arouse more empathy with an organization in crisis.

\section{Study 1}

\subsection{Method}

\subsubsection{Design and stimuli}

We first examined the role that empathy plays in the impact of a crisis on reputational damage. The first hypothesis and research question were addressed by means of a single-factor (crisis type: victim crisis vs. preventable crisis), between-subjects experimental design. By comparing a victim crisis to a preventable crisis, the crisis types inflicting the weakest versus the strongest responsibility attributions are being compared (Coombs, 2007). Crisis type was manipulated using two scenarios about a fictitious organization presented in newspaper articles. The organization was fictitious to avoid that an existing reputation would affect the findings (Dean, 2004). The crisis involved a Dutch energy supplier whose customers' personal data had been leaked online. It was stated in the different newspaper articles that the organization could either have prevented the crisis (i.e. preventable crisis) or not (i.e. victim crisis) (Coombs \& Holladay, 2002). In the victim crisis condition, the organization was hacked, despite it employing high-quality cyber security. In the preventable crisis scenario, the organization had consistently neglected to invest in cyber security, which made it very easy for an employee to publish customers' personal data online accidentally.

\subsubsection{Participants and procedure}

A convenience sample of 69 Belgian adults participated in the study. Respondents received an email or a message through social media inviting them to fill out an online questionnaire. The survey website randomly divided participants between the two experimental conditions. All participants read an introductory text with a description of the company, after which they read the newspaper article. Subsequently, participants completed a questionnaire containing measures of the dependent variables and socio-demographic variables. Participants were an average age of 31 years old $(S D=12.00$, range $=18-61$ years); approximately $38 \%$ were male, and $62 \%$ were female.

\subsubsection{Measures}

Two items from Griffin, Babin, and Darden (1992) $(r=.90$, $p<.001$ ) were used to measure the amount of responsibility attributed to the organization (i.e. "How much do you blame the organization for the crisis?" and "How responsible was the organization for the crisis?") on a seven-point Likert scale.

To measure empathy, we relied on validated measurements of empathy that are commonly used in social-psychological research. As these scales measure empathy toward individuals, participants' empathy with the CEO of the organization (who acted as the spokesperson in the crisis scenario) was measured as a proxy of empathy toward the organization. After all, the CEO is expected to represent the organization as a whole (Men, 2011). Affective empathy was measured using Coke, Batson, and McDavis' (1978) eight-item, seven-point Likert scale ( $\alpha=.90$ ), which assessed participants' empathetic feelings toward the CEO (e.g. sympathy, concern, compassion). In addition, participants indicated to what extent they experienced cognitive empathy toward the CEO on a single-item, seven-point Likert scale ("I tried to imagine 
Table 1

Means and standard deviations for attributions of crisis responsibility, empathy, and post-crisis reputation.

\begin{tabular}{llll}
\hline & $\begin{array}{l}\text { Preventable crisis } \\
M(S D)\end{array}$ & $\begin{array}{l}\text { Victim } \\
\text { crisis } \\
M(S D)\end{array}$ & $\begin{array}{l}\text { Total } \\
M(S D)\end{array}$ \\
\hline $\begin{array}{l}\text { Attributions of crisis } \\
\text { responsibility }\end{array}$ & $6.09(.82)$ & $4.05(1.69)$ & $5.00(1.70)$ \\
$\begin{array}{l}\text { Affective empathy } \\
\text { Cognitive empathy }\end{array}$ & $2.65(.95)$ & $3.39(.86)$ & $3.05(.97)$ \\
Post-crisis reputation & $2.84(1.73)$ & $4.00(1.6)$ & $3.46(1.75)$ \\
& $2.39(.90)$ & $3.42(1.25)$ & $2.94(1.21)$
\end{tabular}

how the CEO might have thought and felt under the given circumstances") adapted from Takaku (2001).

Post-crisis reputation was measured by means of nine items derived from the Reputation Quotient of Fombrun, Gardberg, and Sever (2000). The items included statements such as "This company offers highquality products", "This company has excellent leadership", and "I admire and respect this company". The items were rated on a sevenpoint Likert scale $(\alpha=.88)$. Table 1 shows the means and standard deviations of the constructs

\subsection{Results}

To address the hypothesis and research question, a mediation analysis was conducted by means of Hayes' (2013) PROCESS procedure in SPSS for a serial multiple mediator model (Model 6). To address the research question, crisis type was modeled as affecting post-crisis reputation through three indirect pathways that tested the independent mediating roles of and relationship between (both cognitive and affective) empathy and responsibility attributions. The first pathway is proposed by attribution theory (Weiner et al., 1991) and runs from crisis type to reputation via responsibility attributions only (i.e. controlling for empathy). The second indirect effect passes from crisis type to reputation through both responsibility attributions and empathy sequentially, with responsibility attributions predicted to affect empathy. Hence, taken together, the first two pathways address the relationship between responsibility attributions and empathy as proposed by Davis and Gold (2011) and Fincham et al. (2002). The third indirect effect is proposed by the empathy model of forgiveness (McCullough et al., 1997) and runs from crisis type to reputation via empathy only (i.e. controlling for responsibility attributions). All total, indirect and direct effects are presented in Table 2.

First, the analysis indicated a significant pathway from crisis type to post-crisis reputation via responsibility attributions only $(\mathrm{CI}=[.13$, 1.20]). Hence, the victim crisis inflicted weaker responsibility attributions than the preventable crisis, which translated directly into

Table 2

Total, indirect, and direct effects of crisis type (preventable crisis vs. victim crisis) on post-crisis reputation Note. Crisis type was coded as $0=$ preventable crisis, $1=$ victim crisis. The analysis used 5000 bootstrap samples to estimate $99 \%$ confidence intervals. The effect is significant if the confidence interval does not contain zero.

\begin{tabular}{|c|c|c|c|c|c|}
\hline & $B$ & $S E$ & $p$ & $\begin{array}{l}99 \% \mathrm{CI} \\
\text { (lower) }\end{array}$ & $\begin{array}{l}99 \% \mathrm{CI} \\
\text { (upper) }\end{array}$ \\
\hline Total effects & 1.03 & .27 & $<.001$ & .32 & 1.73 \\
\hline \multicolumn{6}{|l|}{ Specific indirect effects via: } \\
\hline Responsibility attributions & .61 & .21 & & .13 & 1.20 \\
\hline $\begin{array}{l}\text { Responsibility attributions } \rightarrow \\
\text { affective empathy }\end{array}$ & .32 & .12 & & .10 & .71 \\
\hline $\begin{array}{l}\text { Responsibility attributions } \rightarrow \\
\text { cognitive empathy }\end{array}$ & .02 & .04 & & -.12 & .13 \\
\hline Affective empathy & .05 & .15 & & -.30 & .55 \\
\hline Cognitive empathy & -.10 & .08 & & -.36 & .08 \\
\hline Direct effects & .17 & .26 & .53 & -.53 & .86 \\
\hline
\end{tabular}

increased reputation repair (i.e. without passing through empathy). Second, a significant path of crisis type to reputation through responsibility attributions and affective (not cognitive, $\mathrm{CI}=[-.12, .13]$ ) empathy sequentially $(\mathrm{CI}=[.10, .71])$ was established. The victim crisis prompted weaker responsibility attributions than the preventable crisis, which translated into increased affective empathy. Affective empathy in turn minimized reputational damage. Therefore, $\mathrm{H} 1$ is supported, as both empathy and responsibility attributions mediated the crisis type/ reputation relationship. Third, the path from crisis type to reputation via affective $(\mathrm{CI}=[-.30, .55])$ or cognitive $(\mathrm{CI}=[-.36, .08])$ empathy only was not significant. Hence, empathy did not mediate the crisis type/reputation relationship when controlling for responsibility attributions. Finally, the direct effect of crisis type on reputation was nonsignificant $(\mathrm{CI}=[-.53, .86], p=.53)$. Taken together, the results show that the responsibility attributions generated by the crisis type predict post-crisis reputation both directly and indirectly via affective empathy, providing an answer to the RQ on how empathy and responsibility perceptions are related as mediators in the crisis type/reputation relationship. Fig. 1 presents the relationships between crisis type, responsibility attributions, affective empathy and post-crisis reputation.

\subsection{Discussion}

This study illustrates that stakeholders' affective empathy with an organization in crisis helps explain the impact of crises on organizational reputation. The results align with established crisis communication research that stresses the importance of responsibility attributions for explaining the connection between crisis type and post-crisis reputation (Coombs, 2007). However, corroborating findings from research on interpersonal forgiveness (Davis \& Gold, 2011; Fincham et al., 2002), and expanding attempts to move beyond responsibility attributions and integrate the role of stakeholder affect into crisis communication theory (Coombs \& Holladay, 2005), the results establish that affective empathy provides a second explanation for this relationship. When members of the public attribute minimal crisis responsibility to the organization, they will perceive the post-crisis reputation more positively, and this positive impact can in part be explained by an increase in the public's empathy with the organization. Hence, victim crises result in less reputational damage than preventable crises not only because they prompt weaker responsibility attributions but also because they subsequently lead to more empathy from the public.

\section{Study 2}

For two reasons, a follow-up experiment aiming to corroborate the first study's findings was conducted. Because the first study employed only a single crisis scenario to test the hypotheses, the external validity of the findings and their generalizability to other crisis situations may be compromised (Reeves, Yeykelis, \& Cummings, 2016). Furthermore, although numerous social-psychological studies have established that both responsibility attributions and empathy are critical to forgiveness, empirical research on the nature of their relationship remains scarce (Davis \& Gold, 2011). A follow-up study allowed for the assessment of whether the first study's findings are robust over different crisis contexts and for further testing of the relationship between responsibility attributions and empathy.

\subsection{Method}

\subsubsection{Design and stimuli}

The first hypothesis and the research question were addressed with a single-factor (crisis type: victim crisis vs. preventable crisis), betweensubjects experimental design. As in the first study, crisis type was manipulated using two fictitious crisis scenarios presented in newspaper articles. To increase the generalizability of our findings, the scenario 


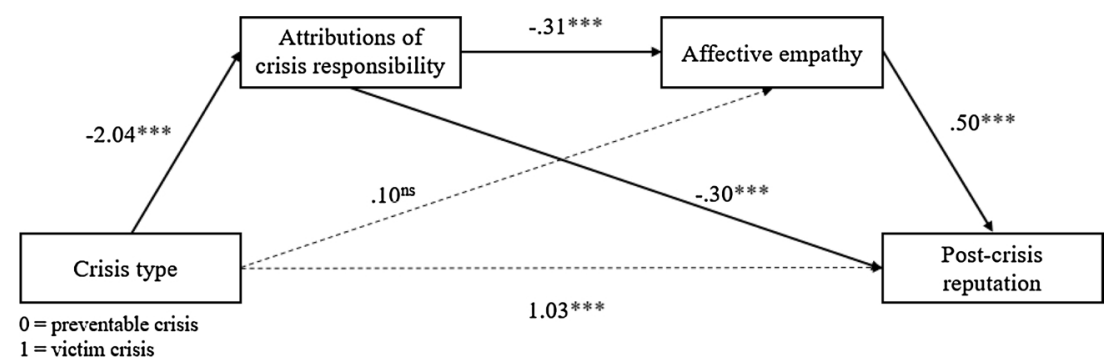

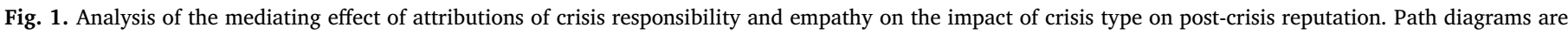
shown with unstandardized regression coefficients (***p $<.001,{ }^{\text {ns }}$ not significant).

involved an operational crisis in which a product was affected, rather than a reputational crisis as in the first study (Coombs, 2015). The scenarios involved the discovery of a carcinogenic coloring agent that has been associated with health issues in the products of a British candy company that claimed to use only natural food coloring. In the victim crisis condition, the article stated that the carcinogenic coloring agents were delivered by an external supplier, and that the company could not have known. The company had knowingly and deliberately used the carcinogenic coloring agents in the preventable crisis condition (Coombs \& Holladay, 2002).

\subsubsection{Participants and procedure}

A convenience sample of 82 Belgian adults participated in the online study. Respondents, contacted via e-mail and social media, received a link to a website that randomly divided them between the two experimental conditions. Respondents read a description of the fictitious company before reading the newspaper article. Subsequently, they completed a questionnaire containing measures of the dependent variables and socio-demographic variables. Participants were an average age of 33 years old $(S D=14.34$, range $=18-64$ years $)$. Approximately $42 \%$ were male and $58 \%$ were female.

\subsubsection{Measures}

Cognitive empathy (Takaku, 2001), affective empathy $(\alpha=.90)$ (Coke et al., 1978), perceptions of organizational responsibility $(r=.88, p<.001)$ (Griffin et al., 1992), and post-crisis reputation $(\alpha=.94)$ (Fombrun et al., 2000) were measured by the same sevenpoint Likert scale employed in the first study. Table 3 presents the means and standard deviations of the constructs

\subsection{Results}

Similar to the first study, a mediation analysis was conducted using Hayes' (2013) PROCESS procedure (Model 6) to address the first hypothesis and research question. The model included responsibility attributions and affective and cognitive empathy as mediators of the effect of crisis type on post-crisis reputation. The same pathways from crisis type to reputation as assessed in the first study were examined again. All total, indirect and direct effects are presented in Table 4.

First, the pathway proposed by attribution theory was tested. The

Table 3

Means and standard deviations for attributions of crisis responsibility, empathy, and post-crisis reputation.

\begin{tabular}{llll}
\hline & $\begin{array}{l}\text { Preventable crisis } \\
M(S D)\end{array}$ & $\begin{array}{l}\text { Victim } \\
\text { crisis } \\
M(S D)\end{array}$ & $\begin{array}{l}\text { Total } \\
M(S D)\end{array}$ \\
\hline $\begin{array}{l}\text { Attributions of crisis } \\
\text { responsibility }\end{array}$ & $6.28(.68)$ & $3.26(1.29)$ & $4.77(1.82)$ \\
$\begin{array}{l}\text { Affective empathy } \\
\text { Cognitive empathy } \\
\text { Post-crisis reputation }\end{array}$ & $1.95(.87)$ & $3.12(1.02)$ & $2.53(1.11)$ \\
\hline
\end{tabular}

Table 4

Total, indirect, and direct effects of crisis type (preventable crisis vs. victim crisis) on post-crisis reputation Note. Crisis type was coded as $0=$ preventable crisis, $1=$ victim crisis. The analysis used 5000 bootstrap samples to estimate $99 \%$ confidence intervals. The effect is significant if the confidence interval does not contain zero.

\begin{tabular}{llllll}
\hline & $B$ & $S E$ & $p$ & $\begin{array}{l}99 \% \mathrm{CI} \\
\text { (lower) }\end{array}$ & $\begin{array}{l}99 \% \mathrm{CI} \\
\text { (upper) }\end{array}$ \\
\hline $\begin{array}{l}\text { Total effects } \\
\text { Specific indirect effects via: }\end{array}$ & 2.07 & .22 & $<.001$ & $\mathbf{1 . 4 9}$ & $\mathbf{2 . 6 5}$ \\
$\quad \begin{array}{l}\text { Responsibility attributions } \\
\text { Responsibility attributions } \rightarrow\end{array}$ & .92 & .24 & & .36 & $\mathbf{1 . 6 2}$ \\
$\begin{array}{l}\text { affective empathy } \\
\text { Responsibility attributions }\end{array}$ & -.03 & .18 & & -.51 & .52 \\
$\quad$ cognitive empathy & .005 & .09 & & -.24 & .31 \\
$\quad \begin{array}{lllll}\text { Affective empathy } \\
\quad \text { Cognitive empathy }\end{array}$ & .54 & .25 & & .04 & $\mathbf{1 . 3 6}$ \\
Direct effects & .05 & .11 & & -.19 & .48 \\
\hline
\end{tabular}

analysis revealed a significant path from crisis type to post-crisis reputation via responsibility attributions only $(\mathrm{CI}=[.36,1.62])$. Hence, the victim crisis generated lower responsibility attributions than the preventable crisis, which directly resulted in increased reputation repair. Second, the pathway from crisis type to reputation through responsibility attributions and empathy in sequence (cf. Davis \& Gold, 2011; Fincham et al., 2002) appeared nonsignificant (affective empathy, $\mathrm{CI}=[-.51, .52]$; cognitive empathy, $\mathrm{CI}=[-.24, .31])$. As such, responsibility attributions and empathy were not correlated as mediators when accounting for the influence of crisis type on both variables. Thus, empathy was not affected by responsibility attributions. Third, the pathway proposed by the empathy model was tested. The analysis detected a significant pathway from crisis type to reputation through affective (not cognitive, $\mathrm{CI}=[-.19, .48]$ ) empathy only $(\mathrm{CI}=[.04$, 1.36]). Hence, regardless of levels of attributed responsibility, the victim crisis induced more affective empathy than the preventable crisis. Affective empathy, in turn, reduced reputational damage. Finally, the direct effect of crisis type on reputation was nonsignificant ( $\mathrm{CI}=$ $[-.39,1.38], p=.15)$. Taken together, the results illustrate that empathy and responsibility attributions co-mediate the effect of crisis type on post-crisis reputation independently, providing support for $\mathrm{H} 1$ which proposed that both empathy and responsibility attributions would mediate the crisis-type/reputation relationship. However, these results provide a different answer to the RQ as given by the results of the first study, which revealed that responsibility attributions affected empathy. Fig. 2 summarizes the relationships between the variables.

\subsection{Discussion}

Inspired by attribution theory, crisis communication scholars have consistently highlighted a connection between crisis type and reputation, explained by the crisis responsibility generated by the crisis type (Claeys et al., 2010; Coombs \& Holladay, 2002; Verhoeven et al., 2012). The results of both studies one and two reaffirm that responsibility 


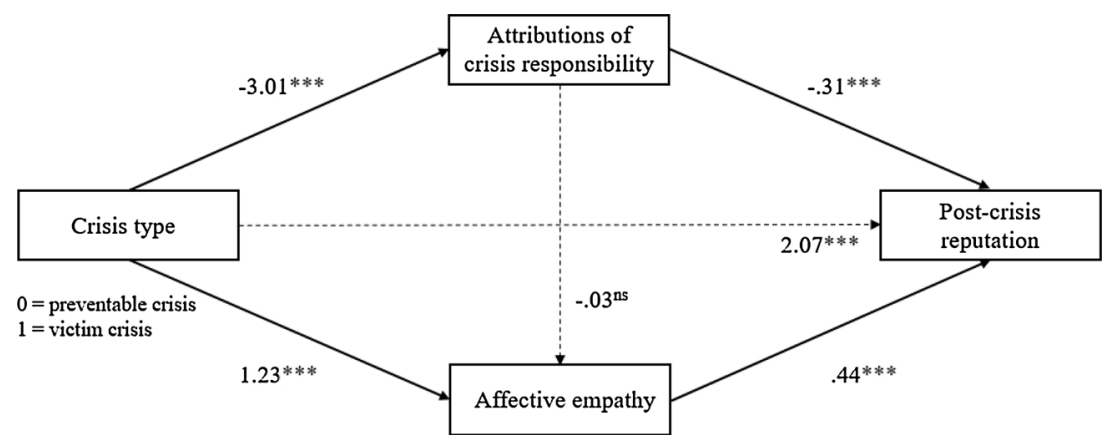

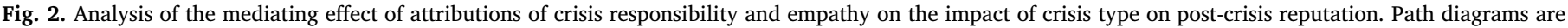
shown with unstandardized regression coefficients (***p $<.001,{ }^{*}$ not significant).

attributions predict the reputational damage inflicted by crises but reveal that empathy also plays an important role in this process.

However, these studies offer conflicting views on how responsibility attributions and affective empathy are related as predictors of postcrisis reputation. The first study shows that responsibility perceptions affect the extent to which empathy is aroused. The second study indicates that responsibility attributions and empathy mediate the crisis type-reputation relationship independently; when organizations are confronted with a victim crisis rather than a preventable one, the public attributes less crisis responsibility to the organization on the one hand and experiences more affective empathy with the organization on the other hand. As such, while the first study's findings align with those from social-psychological studies illustrating that empathy is affected by responsibility attributions (Davis \& Gold, 2011; Fincham et al., 2002), the second study's results support attribution theory (Weiner et al., 1991) and the empathy model of forgiveness (McCullough et al., 1997) as parallel perspectives that emphasize the individual importance of responsibility attributions and empathy, respectively. Nevertheless, the second study's findings again stress the importance of empathydriven processes in the field of crisis communication, which thus far has only integrated processes derived from attribution theory into its frameworks. As such, it is important to examine the role of empathy not only as an explanation for the impact of crisis types but also for the effect of crisis response strategies.

\section{Study 3}

\subsection{Method}

\subsubsection{Design and stimuli}

A single-factor (crisis response strategy: apology vs. denial), between-subjects experiment was conducted to address the second hypothesis. Experimental studies often compare the effects of apologies to denial (Coombs \& Holladay, 2008), as they lie at opposite ends of a continuum ranging from accommodative to defensive response strategies (Coombs, 2007). Each participant read the same introductory text describing a fictitious crisis involving a Finnish tire manufacturer that sold a number of tires that were damaged due to a manufacturing error. The organization was aware of this product failure but decided to sell the tires anyway to avoid delays. The faulty tires caused a school bus to crash, several children received minor injuries. According to experts, the tires caused the accident, and the organization thus could have prevented the event. As such, the scenario described a preventable crisis, the type of crisis that poses the highest reputational threat (Coombs, 2007) and for which increasing the public's empathy would prove especially challenging but beneficial.

After reading the scenario, participants read a text that described the CEO's response to the incident. In the apology condition, the CEO acknowledged responsibility and offered apologies to all those involved. In the deny condition, the CEO firmly denied that the tires could have endangered passengers and claimed that the organization could not have avoided the accident (Coombs, 2007).

\subsubsection{Participants and procedure}

A convenience sample of 63 Belgian adults participated in the online study. Participants received an e-mail or a message on social media with a link to the website that assigned them randomly to the experimental conditions. All participants read the crisis scenario and the manipulated organizational reactions to the events. Subsequently, they completed a questionnaire with measures of the dependent variables and socio-demographic variables. Participants were an average age of 31 years old $(S D=13.65$, range $=19-76$ years). Approximately $57 \%$ were male, and $43 \%$ were female.

\subsubsection{Measures}

Participants rated on a seven-point semantic differential scale (rejects all responsibility for the crisis - accepts full responsibility for the crisis) to what extent they perceived that the organization took responsibility for the crisis to check the manipulation of crisis response strategy (Coombs, 2007). Cognitive empathy (Takaku, 2001), affective empathy $(\alpha=.85)$ (Coke et al., 1978), and post-crisis reputation ( $\alpha=.90$ ) (Fombrun et al., 2000) were measured using the same sevenpoint Likert scales employed in the first two studies (see Table 5).

\subsection{Results}

\subsubsection{Manipulation check}

An independent samples $t$-test indicated that participants in the apology condition $(M=5.73, S D=1.08)$ perceived that the organization took more responsibility for the crisis than participants in the denial condition $(M=1.45, S D=.83 ; t(61)=17.69, \mathrm{p}<.001)$.

\subsubsection{Test of hypothesis}

To address the second hypothesis, a mediation analysis was conducted by means of Hayes' (2013) PROCESS procedure for a simple mediation model (Model 4; 5000 bootstrap samples; 99\% confidence intervals). The model included both cognitive and affective empathy as mediators in the path from crisis response strategy to post-crisis reputation.

The total effect model indicated that crisis response strategy, overall, did not affect reputation $(B=.07, S E=.22, \mathrm{CI}=[-.51, .66]$,

Table 5

Means and standard deviations for empathy and post-crisis reputation.

\begin{tabular}{llll}
\hline & $\begin{array}{l}\text { Denial } \\
M(S D)\end{array}$ & $\begin{array}{l}\text { Apology } \\
M(S D)\end{array}$ & $\begin{array}{l}\text { Total } \\
M(S D)\end{array}$ \\
\hline Affective empathy & $2.05(.95)$ & $2.94(1.11)$ & $2.47(1.11)$ \\
Cognitive empathy & $3.94(1.89)$ & $4.47(1.59)$ & $4.19(1.76)$ \\
Post-crisis reputation & $2.40(.90)$ & $2.47(.85)$ & $2.44(.87)$ \\
\hline
\end{tabular}




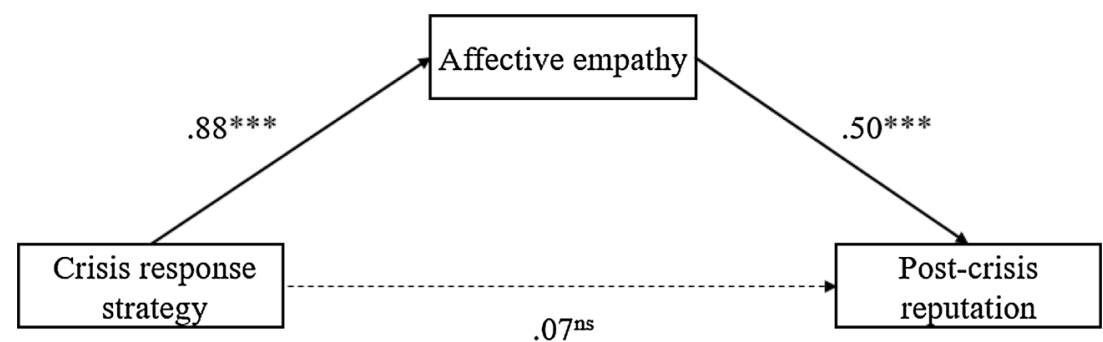

$0=$ denial

$1=$ apology

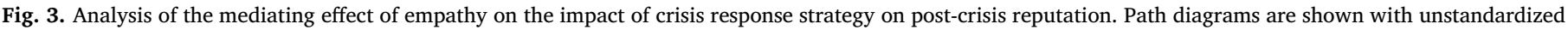
regression coefficients $\left(* * * p<.001,{ }^{\text {ns }}\right.$ not significant).

$p=.74)$. Hence, the apology-strategy did not lead to increased reputation repair compared to denial, contrary to what was expected in H2. However, the analysis did reveal a significant indirect effect of response strategy on reputation through affective (not cognitive, $C I=$ $[-.06, .35])$ empathy $(B=.44, S E=.16, \mathrm{CI}=[.10, .91])$. An apology induced more affective empathy than denial, which then minimized reputational damage. Therefore, $\mathrm{H} 2$ receives partial support. The direct effect of crisis response strategy on post-crisis reputation was nonsignificant $(B=-.37, S E=.20, \mathrm{CI}=[-.89, .16], p=.07)$. Fig. 3 presents the correlations between the variables.

\subsection{Discussion}

While crisis communication research has established repeatedly that apologies are more effective for repairing reputation than denial (e.g. Kim et al., 2009), no research has empirically identified the process underlying apologies' effectiveness. Thus, the aim of the third study was to explain the effectiveness of apologies by taking a closer look at whether or not they induce empathy for the organization. First, the results support the finding from the first two studies that the public's affective empathy minimizes reputational damage. Second, while the first two studies showed that empathy determines stakeholder responses to crises, the third study goes a step further by identifying empathy as a component in the process of reputation repair that can be affected by crisis communication and explain its effectiveness.

The public experiences more affective empathy with an organization that apologizes for a preventable crisis than with an organization that denies responsibility. Affective empathy, in turn, stimulates members of the public to evaluate the organizational reputation more positively. Therefore, the findings align with social-psychological research showing that empathy mediates the relationship between offering an apology and receiving forgiveness (Davis \& Gold, 2011; McCullough et al., 1997, 1998) and provide a deeper understanding of the mechanisms underlying corporate apologies' effectiveness in restoring reputation, as established in prior research (e.g. Kim et al., 2009).

However, an apology in itself unexpectedly did not lead to more positive organizational perceptions. Denial can indeed protect reputation if the strategy is accepted and results in the public's conviction that the organization is not responsible for a crisis (Claeys et al., 2010; Coombs, 2007: Fuoli et al., 2017). The beneficial impact of empathy as established in our study might thus have been overturned by a positive effect of a reduction in responsibility attributions if participants believed the denial to be true. This is subject to further research, however, as the current study did not assess if the denial was considered valid through a measurement of account acceptance.

\section{General discussion and conclusions}

By introducing stakeholders' empathy as an explanatory factor in crisis situations, our three experimental studies continue to improve the understanding of how stakeholders perceive organizational reputation in response to crises and how crisis communication affects these perceptions. Each study confirmed our initial proposition that crisis communication research should consider empathy as an important factor in determining the post-crisis reputation.

First, the findings expand our understanding of how crises affect public perceptions of organizations by illustrating that the public's affective empathy explains the well-established relationship between crisis type and reputation. Prior research has demonstrated that organizations confronted with a victim crisis suffer less reputational damage than those confronted with a preventable crisis because the former comes with lower responsibility attributions. Our studies show that victim crises also result in more affective empathy toward an organization, which helps reduce reputational damage. Both studies therefore stress the importance of affective empathy in the crisis type/reputation relationship and, as such, extend explorative studies that have called for the integration of stakeholders' affective reactions to crises into (situational) crisis communication theory (Coombs \& Holladay, 2005; Mcdonald et al., 2010). More research is needed, however, to further clarify the relationship that our studies have established between responsibility attributions and empathy. The first study found that levels of empathy are determined by responsibility attributions, while the second study found that empathy mediates the effect of crisis type on reputation independently from responsibility attributions. Which models of the nature between responsibility attributions and empathy as explanatory factors take the upper hand, then is likely to depend upon situational factors that might have differed between the crisis scenarios of the two studies. Social-psychological research argues that the extent to which empathy develops and its impact are determined by situational factors, such as the severity (Riek \& Mania, 2012) and nature (e.g. integrity- vs. competence-based) (Kim, Ferrin, Cooper, \& Dirks, 2004) of the transgression. Such factors are also relevant in an organizational context and have been shown to affect perceptions of organizational crisis responsibility as well (e.g. Zhou \& Ki, 2018; Fuoli et al., 2017, respectively). Participants might have judged the crisis from the second study more severe, as it involved the distribution of products that might cause health issues. In addition, the preventable version of this crisis in which the company deliberately used harmful coloring agents in its products can be considered integrity-based, whereas the preventable crisis involving the leak of customers' data in the first study is more likely to be considered competence-based. Other situational factors that are relevant in the contexts of interpersonal conflicts and organizational crises that are worth considering as moderators of the relationship between empathy and responsibility attributions are, for instance, the nature of the victims (Park \& Len-Ríos, 2012), organizational crisis history (Coombs, 2007), and organizational pre-crisis reputation (Decker, 2012). Nevertheless, the two experiments consistently showed that both responsibility attributions and empathy determine the reputational damage inflicted by crises.

Importantly, a more thorough understanding of how stakeholders respond to crises informs the strategic and effective use of crisis 
communication (Coombs \& Holladay, 2005). We know from SCCT that crisis response strategies should be adapted to the crisis type, because this crisis type determines reputational damage through attributions of responsibility (Coombs, 2007). The first two studies show us that in determining a suitable crisis response strategy, we should not only consider attributions of responsibility but also the level of the public's empathy with the organization. A more accommodative crisis response may not only be required when attributions of responsibility are high (cf. Coombs, 2007), but also when a certain crisis results in low levels of empathy. In addition, the third study shows that the actual crisis response strategy applied can have an effect on empathy as well. The findings have showed that an organizational apology repairs reputation by increasing empathy from the public, while a denial strategy does not succeed in raising empathic concern for an organization in trouble. This finding not only offers an explanation for the consistent finding that apologies are an effective crisis response strategy irrespective of the crisis type (Claeys et al., 2010; Kim et al., 2009), it also initiates further research on how public empathy can be affected by crisis communication efforts.

To conclude, empathy provides a second important variable besides attributions of responsibility to understand the connection between crisis situations, crisis communication, and crisis outcomes. As such, empathy must be taken into consideration when examining and explaining the impact of crises and crisis communication.

\section{Limitations and further research}

The results and limitations of these three studies offer a number of relevant directions for further research that could help deepen our knowledge of the role empathy plays in the crisis communication process.

First, the studies consistently show that stakeholders' affective, not cognitive, empathy affects post-crisis reputation. Social-psychological research has predominantly focused on the role of affective empathy in processes of forgiveness (Fehr et al., 2010). Similarly, the studies that contributed to our hypotheses did not examine cognitive empathy (Davis \& Gold, 2011; Fincham et al., 2002; McCullough et al., 1997, 1998). However, cognitive empathy is considered a strong motivator of prosocial behavior (Davis, 2005). Moreover, victims that are instructed to take the transgressor's perspective on a situation are more likely to forgive (Takaku, 2001). Hence, further research should investigate how crisis communication strategies can affect both cognitive and affective empathy and should explore the conditions that determine the dominant component in shaping public perceptions.

Second, the one-item scale used to measure cognitive empathy in our studies might have oversimplified the dimensionality of cognitive empathy as a construct (Baron-Cohen \& Wheelwright, 2004). In addition, empathy was measured in all three studies. Further research could experimentally manipulate empathy to further examine its effects on crisis outcomes, by, for instance, giving participants perspective-taking instructions (Takaku, 2001).

Third, the scenarios in our studies featured a clearly identifiable spokesperson (the companies' CEOs) toward whom the public could develop empathy. Therefore, our results cannot be confidently generalized to situations in which an organization in crisis opts to address the public without putting forward a spokesperson. In line with this, further research could measure empathy toward organizations as a whole instead of measuring empathy toward the CEO. As consumers attribute human characteristics and traits to organizations (Keller, 2013), it is likely that the public can also develop empathy toward organizations as entities. In addition, it might prove problematic to treat empathy toward a CEO as a direct proxy of empathy toward an organization in cases in which a CEO is perceived as distinct from his or her organization.

Fourth, study three did not include a measurement of account acceptance. The degree to which participants believed that a crisis response strategy was appropriate could have determined the post-crisis reputation (Coombs \& Holladay, 2008). Levels of participants' account acceptance could thus have provided a better understanding for why no effect of crisis response strategy on reputation was established.

Finally, as the findings illustrate that empathy from the public facilitates reputation repair, research should further investigate how communication efforts affect empathy. For example, compensating victims or expressing sympathy toward those affected by the crisis are both response strategies that are, like an apology, highly accommodative toward victims (Coombs \& Holladay, 2008) and as such might trigger (affective) empathy as well. Explaining why the crisis events occurred is another communicative effort that is expected to arouse (especially cognitive) empathy (Riek \& Mania, 2012). Furthermore, research in neurosciences indicates that affective empathy is aroused relatively automatically when observing another's emotions (Blair, 2005). Recent crisis communication research has shown that reputational damage is minimized when spokespersons communicate their emotions about the events (Claeys \& Cauberghe, 2014). Future research should examine whether the positive impact of emotional crisis communication can be explained through empathy. In addition, similarity in terms of demographic variables (e.g. gender) between the spokesperson of an organization and the addressed audience is also likely to trigger empathy (Crijns, Claeys, Cauberghe, \& Hudders, 2017). Overall, our findings suggest that empathy may prove vital in explaining the effects of a number of crisis communication strategies. As such, empathy can provide an exciting focus for further crisis communication research.

\section{Acknowledgement}

This research was supported in part by a grant from the Research Foundation - Flanders (FWO) [grant number G070716N].

\section{References}

Baron-Cohen, S., \& Wheelwright, S. (2004). The empathy quotient: An investigation of adults with Asperger syndrome or high functioning autism, and normal sex differences. Journal of Autism and Developmental Disorders, 34(2), 163-175. https://doi. org/10.1023/b:jadd.0000022607.19833.00.

Blair, R. J. R. (2005). Responding to the emotions of others: Dissociating forms of em pathy through the study of typical and psychiatric populations. Consciousness and Cognition, 14(4), 698-718. https://doi.org/10.1016/j.concog.2005.06.004.

Claeys, A.-S., \& Cauberghe, V. (2014). What makes crisis response strategies work? The impact of crisis involvement and message framing. Journal of Business Research, 67(2), 182-189. https://doi.org/10.1016/j.jbusres.2012.10.005.

Claeys, A.-S., Cauberghe, V., \& Vyncke, P. (2010). Restoring reputations in times of crisis: An experimental study of the situational crisis communication theory and the moderating effects of locus of control. Public Relations Review, 36(3), 256-262. https:// doi.org/10.1016/j.pubrev.2010.05.004.

Coke, J. S., Batson, C. D., \& McDavis, K. (1978). Empathic mediation of helping: A twostage model. Journal of Personality and Social Psychology, 36(7), 752-766. https://doi. org/10.1037/0022-3514.36.7.752.

Coombs, W. T. (1998). An analytic framework for crisis situations: Better responses from a better understanding of the situation. Journal of Public Relations Research, 10(3), 177-191. https://doi.org/10.1207/s1532754xjprr1003 02.

Coombs, W. T. (2007). Protecting organization reputations during a crisis: The development and application of situational crisis communication theory. Corporate Reputation Review, 10(3), 163-176. https://doi.org/10.1057/palgrave.crr.1550049.

Coombs, W. T. (2015). Ongoing crisis communication: Planning, managing, and responding. Thousand Oaks, CA: Sage.

Coombs, W. T., \& Holladay, S. J. (2005). An exploratory study of stakeholder emotions: Affect and crises. In N. Ashkanasy, W. J. Zerbe, \& C. E. J. Härtel (Eds.). The effect of affect in organizational settings: Research on emotion in organizations (pp. 263-280). New York: Elsevier.

Coombs, W. T., \& Holladay, S. J. (2008). Comparing apology to equivalent crisis response strategies: Clarifying apology's role and value in crisis communication. Public Relations Review, 34(3), 252-257. https://doi.org/10.1016/j.pubrev.2008.04.001.

Coombs, W. T., \& Holladay, S. J. (2002). Helping crisis managers protect reputational assets: Initial tests of the situational crisis communication theory. Management Communication Quarterly, 16(2), 165-186. https://doi.org/10.1207/ S1532754XJPRR1304_03.

Coombs, W. T., Holladay, S. J., \& Claeys, A.-S. (2016). Debunking the myth of denial's effectiveness in crisis communication: Context matters. Journal of Communication Management, 20(4), 381-395. https://doi.org/10.1108/JCOM-06-2016-0042.

Crijns, H., Claeys, A.-S., Cauberghe, V., \& Hudders, L. (2017). Who says what during 
crises? A study about the interplay between gender similarity with the spokesperson and crisis response strategy. Journal of Business Research, 79(1), 143-151. https://doi. org/10.1016/j.jbusres.2017.06.01.

Davis, M. H. (2005). Empathy and prosocial behavior. In D. A. Schroeder, \& W. G. Graziano (Eds.). The Oxford handbook of prosocial behavior (pp. 282-306). New York: Oxford University Press.

Davis, J. R., \& Gold, G. J. (2011). An examination of emotional empathy, attributions of stability, and the link between perceived remorse and forgiveness. Personality and Individual Differences, 50(3), 392-397. https://doi.org/10.1016/j.paid.2010.10.031.

Dean, D. H. (2004). Consumer reaction to negative publicity: Effects of corporate reputation, response, and responsibility for a crisis event. Journal of Business Communication, 41(2), 192-211. https://doi.org/10.1177/0021943603261748.

Decety, J., \& Jackson, P. L. (2004). The functional architecture of human empathy. Behavioral and Cognitive Neuroscience Reviews, 3(2), 71-100. https://doi.org/10. $1177 / 1534582304267187$.

Decker, W. H. (2012). A firm's image following alleged wrongdoing: Effects of the firm's prior reputation and response to the allegation. Corporate Reputation Review, 15(1), 20-30. https://doi.org/10.1057/crr.2011.27.

Fediuk, T. A., Coombs, W. T., \& Botero, I. C. (2012). Exploring crisis from a receiver perspective: Understanding stakeholder reactions during crisis events. In W. T. Coombs, \& S. J. Holladay (Eds.). Handbook of crisis communication (pp. 221-242). Boston, MA: Wiley-Blackwell.

Fehr, R., Gelfand, M. J., \& Nag, M. (2010). The road to forgiveness: A meta-analyticsynthesis of its situational and dispositional correlates. Psychological Bulletin 136(5), 894-914. https://doi.org/10.1037/a0019993.

Fincham, F. D., Paleari, G. F., \& Regalia, C. (2002). Forgiveness in marriage: The role of relationship quality, attributions, and empathy. Personal Relationships, 9(1), 27-37. https://doi.org/10.1111/1475-6811.00002.

Fombrun, C. J., Gardberg, N. A., \& Sever, J. M. (2000). The Reputation Quotient ${ }^{\mathrm{SM}}$ : A multi-stakeholder measure of corporate reputation. Journal of Brand Management, 7(4), 241-255. https://doi.org/10.1057/bm.2000.10.

Fuoli, M., van de Weijer, J., \& Paradis, C. (2017). Denial outperforms apology in repairing organizational trust despite strong evidence of guilt. Public Relations Review, 43(3), 645-660. https://doi.org/10.1016/j.pubrev.2017.07.007.

Griffin, M., Babin, B. J., \& Darden, W. R. (1992). Consumer assessments of responsibility for product-related injuries: The impact of regulations, warnings, and promotional policies. Advances in Consumer Research, 19(1), 870-878.

Hayes, A. F. (2013). Introduction to mediation, moderation, and conditional process analysis: A regression-based approach. New York: Guilford.

Keller, K. L. (2013). Strategic brand management: Building, measuring and managing brand equity. London: Pearson Education Limited.

Kim, P. H., Ferrin, D. L., Cooper, C. D., \& Dirks, K. T. (2004). Removing the shadow ofsuspicion: The effects of apology versus denial for repairing competence- versusintegrity-based trust violations. The Journal of Applied Psychology, 89(1), 104-118. https://doi.org/10.1037/0021-9010.89.1.104.

Kim, S., Avery, E. J., \& Lariscy, R. W. (2009). Are crisis communicators practicing what wepreach? An evaluation of crisis response strategy analyzed in public relations researchfrom 1991 to 2009. Public Relations Review, 35(4), 446-448. https://doi.org/ 10.1016/j.pubrev.2009.08.002.

Lee, B. K. (2004). Audience-oriented approach to crisis communication: A study of Hong Kong consumers' evaluation of an organizational crisis. Communication Research, 31(5), 600-618. https://doi.org/10.1177/0093650204267936.

Mcdonald, M. L., Sparks, B., \& Glendon, A. I. (2010). Stakeholder reactions to company crisis communication and causes. Public Relations Review, 36(3), 263-271. https:// doi.org/10.1016/j.pubrev.2010.04.004.

McCullough, M. E., Rachal, K. C., Sandage, S. J., Worthington, J. E. L., Brown, S. W., \& Hight, T. L. (1998). Interpersonal forgiving in close relationships: II. Theoretical elaboration and measurement. Journal of Personality and Social Psychology, 75(6), 1586-1603. https://doi.org/10.1037/0022-3514.75.6.1586.

McCullough, M. E., Worthington, E. L., \& Rachal, K. C. (1997). Interpersonal forgiving in close relationships. Journal of Personality and Social Psychology, 73(2), 321-336. https://doi.org/10.1037//0022-3514.73.2.321.

Men, L. J. (2011). CEO credibility, perceived organizational reputation, and employee engagement. Public Relations Review, 38(1), 171-173. https://doi.org/10.1016/j. pubrev.2011.12.011.

Park, S. A., \& Len-Ríos, M. E. (2012). Who suffers? The effect of injured party on attributions of crisis responsibility. In W. T. Coombs, \& S. J. Holladay (Eds.). Handbook of crisis communication (pp. 65-90). Boston, MA: Wiley-Blackwell.

Reeves, B., Yeykelis, L., \& Cummings, J. J. (2016). The use of media in media psychology. Media Psychology, 19(1), 49-71. https://doi.org/10.1080/15213269.2015.1030083.

Riek, B. M., \& Mania, E. W. (2012). The antecedents and consequences of interpersonal forgiveness: A meta-analytic review. Personal Relationships, 19(2), 304-325. https:// doi.org/10.1111/j.1475-6811.2011.01363.x.

Sisco, H. F. (2012). Nonprofit in crisis: An examination of the applicability of situationalcrisis communication theory. Journal of Public Relations Research, 24(1), 1-17. https://doi.org/10.1080/1062726X.2011.582207.

Takaku, S. (2001). The effects of apology and perspective taking on interpersonal forgiveness: A dissonance-attribution model of interpersonal forgiveness. The Journal of Social Psychology, 141(4), 494-508. https://doi.org/10.1080/00224540109600567.

Tomlinson, E. C., Dineen, B. R., \& Lewicki, R. J. (2004). The road to reconciliation:Antecedents of victim willingness to reconcile following a broken promise. Journal of Management, 30(2), 165-187. https://doi.org/10.1016/j.jm. 2003.01.003.

Verhoeven, J. W. M., Van Hoof, J. J., Ter Keurs, H., \& Van Vuuren, M. (2012). Effects ofapologies and crisis responsibility on corporate and spokesperson reputation. Public Relations Review, 38(3), 501-504. https://doi.org/10.1016/j.pubrev.2012.02.002.

Weiner, B. (1986). An attributional theory of motivation and emotion. New York, NY: Springer-Verlag.

Weiner, B., Graham, S., Peter, O., \& Zmuidinas, M. (1991). Public confession andforgiveness. Journal of Personality, 59(2), 281-312. https://doi.org/10.1111/j. 14676494.1991.tb00777.x.

Zhou, Z., \& Ki, E.-J. (2018). Does severity matter?: An investigation of crisis severity fromdefensive attribution theory perspective. Public Relations Review, 21(4) 610-618. https://doi.org/10.1016/j.pubrev.2018.08.008. 